\title{
Learning design Rashomon I - supporting the design of one lesson through different approaches
}

Donatella Persico ${ }^{\mathrm{a} *}$, Francesca Pozzi ${ }^{\mathrm{a}}$, Stamatina Anastopoulou ${ }^{\mathrm{b}}$, Gráinne Conole ${ }^{\mathrm{c}}$, Brock Craft ${ }^{\mathrm{d}}$, Yannis Dimitriadis ${ }^{\mathrm{e}}$, Davinia Hernández-Leo ${ }^{\mathrm{f}}$, Yael Kali ${ }^{\mathrm{g}}$, Yishay Mor ${ }^{\mathrm{h}}$, Mar Pérez-Sanagustín ${ }^{\mathrm{i}}$, and Helen Walmsley ${ }^{\mathrm{j}}$

${ }^{a}$ Istituto per le Tecnologie Didattiche, Consiglio Nazionale delle Ricerche, Genova, Italy; ${ }^{b}$ Department of Information and Communication Systems, University of The Aegean, Athens, Greece; ${ }^{c}$ Institute of Learning Innovation, Leicester University, Leister, UK; ${ }^{d}$ London Knowledge Lab, Institute of Education, London, UK; ${ }^{e}$ GSIC-EMIC Group, School of Telecommunications Engineering, Universidad de Valladolid, Valladolid, Spain; ${ }^{f}$ Information and Communications Technologies Department, Universitat Pompeu Fabra, Barcelona, Spain; ${ }^{g}$ Technologies in Education Graduate Program, Faculty of Education, University of Haifa, Haifa, Israel; ${ }^{h}$ Institute of Educational Technology, Open University, Milton Keynes, UK; ${ }^{i}$ Gradient Lab, GAST, Universidad Carlos III de Madrid, Madrid, Spain; ${ }^{j}$ Learning Development \& Innovation, Staffordshire University, Stoke-on-Trent, UK

(Received 6 December 2012; final version received 10 June 2013)

This paper presents and compares a variety of approaches that have been developed to guide the decision-making process in learning design. Together with the companion Learning Design Rashomon II (Prieto et al., 2013), devoted to existing tools to support the same process, it aims to provide a view on relevant research results in this field. The common thread followed in these two contributions is inspired by Kurosawa's Rashomon film, which takes multiple perspectives on the same action. Similarly, in this paper, Rashomon I, a lesson on "Healthy Eating" is analysed according to five different approaches, while the Rashomon II paper is used to exemplify the affordances of different tools. For this reason, this paper does not follow the conventional structure of research papers (research question, method, results and discussion), but rather it moves from an introduction providing the rationale for the paper, to a description of the five different approaches to learning design (the 4SPPIces Model, the 4Ts, the e-Design Template, the Design Principles Database and the Design Narrative) and then to a discussion of their similarities and differences to inform the choice of potential users.

Keywords: learning design approaches; pedagogical planning; inquiry learning

\section{Introduction}

Over the last 12 years, the research field of learning design has attracted the attention of many researchers because of its promise to provide powerful scaffolds for pedagogically informed design of learning activities that make effective use of technology. Consequently, the recent evolution of this field has been lively and dynamic, and researchers and practitioners have followed different paths to meet a common need: improving the quality and facilitating the implementation of technology-enhanced

*Corresponding author. Email: persico@itd.cnr.it

Research in Learning Technology 2013. (C) 2013 D. Persico et al. Research in Learning Technology is the journal of the Association for Learning Technology (ALT), a UK-based professional and scholarly society and membership organisation. ALT is registered charity number 1063519. http://www.alt.ac.uk/. This is an Open Access article distributed under the terms of the Creative Commons Attribution 3.0 Unported (CC BY 3.0) Licence (http://creativecommons.org/licenses/by/3.0/) permitting use, reuse, distribution and transmission, and reproduction in any medium, provided the original work is properly cited. 


\section{Persico et al.}

learning (TEL) practice in educational contexts. Many national and international projects [Learning Design Grid (LDG) Theme Team, ${ }^{1}$ METIS Project, ${ }^{2}$ JISC project $^{3}$ ] as well as publications addressing this issue testify to these efforts and their progress (Britain 2004; Conole 2013; Goodyear and Retalis 2010; Laurillard 2012; Lockyer et al. 2009; The Larnaca Declaration on Learning Design 2012).

Although the term "learning design" was coined in the late 1990s, the concept has a longer tradition, because it is rooted in the "instructional design" research area that dates back to World War II (Reiser 2001). As a matter of fact, the definition of the term "learning design" and its distinction from "instructional design" and the similar, less frequent expression "pedagogical planning" (Earp and Pozzi 2006; Gutiérrez et al. 2007) is still debated (Mor and Craft 2012; Dobozy 2011), but the delineation of the borders between these areas of work and, more generally, the discussion of the terminological aspects of this sector is beyond our objectives here. For the purposes of this paper, it is relevant to know that learning design aims to devise approaches and tools to assist teachers/designers in planning educational events of various kinds, based on pedagogically sound criteria for the identification of learning objectives, appropriate learning strategies, assessment criteria, digital tools and media.

The state of the art in this area is characterised by the co-existence of a plethora of methods and tools (Conole 2013), some of which are general purpose; that is, they are not related to any specific type of pedagogical approach or learning theory and thus have the ambition of covering a broad range of learning contexts, while others are focused on one pedagogical approach and thus lend themselves better to support the design of specific kinds of activity. As a consequence of such a richness of methods and tools, it has become more and more difficult to know them all, let alone be able to choose the most suitable and thus take advantage of its potentialities. Most researchers or practitioners have tried just a handful of the existing approaches and tools, and few people are likely to have enough time and suitable opportunities to use and compare several of them and thus appreciate their differences.

Hence, the motivation for the two "Rashomon" papers of this journal issue. In Rashomon I, this paper, a single design is captured using a variety of learning design approaches. In Rashomon II (Prieto et al., 2013), the same design is used to demonstrate a number of tools for learning design. Both papers are aimed at fostering reflections about the differences and similarities among the chosen approaches and tools.

We take our inspiration from the internationally acclaimed film, Rashomon (1950), by the late Japanese film director, Akira Kurosawa. Rashomon is notable not only because it introduced Japanese cinema to Western audiences but also because of the novel plot device used by Kurosawa of revealing the same narrative (a mysterious murder) from the perspectives of three different characters. Borrowing from and extending Kurosawa's clever conceit, in these papers we will examine the same design from different perspectives. We will use a scenario ${ }^{4}$ on "Healthy Eating" (Anastopoulou et al. 2012) developed within the Personal Inquiry (PI) project ${ }^{5}$ and analyse it through different approaches and tools. In doing so, we are also building on the tradition of Vignollet, Martel, and Burgos (2008), Botturi et al. (2007) and PérezSanagustín et al. (2012a), who have done similar exercises in the past.

The Healthy Eating scenario was chosen because it is a well-documented case, which has been researched and reported in the literature, and incorporates a rich pedagogy, involving the use of several activities in several locations, supported by several tools. Since we are presenting different models and methodologies, it was 
important to select a complex enough scenario to demonstrate how all the models presented can describe it. Although there are many other examples that fit these criteria, this particular scenario also has the advantage that one of its authors is among the authors of this paper and yet none of the authors of the approaches described in the paper was involved in its design and experimentation, so they could take an unbiased stance towards it.

Specifically, for the purpose of this paper, we have engaged in an exercise, consisting of taking one lesson from the "Healthy Eating" scenario and tried to imagine how each approach would have served the design and planning process. Of course this is an a posteriori exercise, but the idea here is to illustrate the different perspectives one may assume when looking at a single activity, and possibly highlight the various features one can bring to light by adopting one approach or the other.

The approaches considered in this paper are:

- The 4SPPIces Model;

- The 4Ts;

- The e-Design Template;

- The Design Principles Database (DPD);

- The Design Narrative.

These five approaches have been chosen because they are the direct expression of the authors of this paper. This implies that the paper is not exhaustive and its aim is not to provide a complete overview of the field, but rather to show that different approaches to learning design exist, each one offering different features to support the learning design process. In particular, the first two models (4SPPIces Model and 4Ts) are examples of the kind of support that can be offered when designers are engaged in ideating and planning learning activities explicitly inspired by a specific pedagogical approach (e.g. online collaborative learning); the following two models (e-Design Template and DPD) are examples of how to support designers choosing among different pedagogical principles and then applying them during the design process; the last example (Design Narrative) is an example of how it is possible to support not only the design process itself, but also the enactment of a learning design.

The joint effort to develop this paper was organised as follows: first of all, the authors of each approach worked separately on the chosen scenario and used their approach to produce the learning design and a description of the related design process. Then, the authors gathered the results of their exercises and wrote the rest of the paper in a collaborative way.

In the following, after a brief introduction of the chosen scenario, the results of the exercise for each of the above approaches are presented in five separate sections. To conclude, the discussion presents some reflections based on a comparison of the five approaches, together with an analysis of their strengths and weaknesses.

\section{The "Healthy Eating" scenario}

In the "Healthy Eating" scenario, students conduct a guided inquiry into their eating habits, recording the food they eat and investigating its nutritional value. As already mentioned, we have selected this particular scenario because it is well documented by 


\section{Persico et al.}

the PI project (Anastopoulou et al. 2012), and its topic is widely known and easy to understand (compared to other specialty subject domains).

The goals of the whole sequence are for students to:

- raise their awareness of the importance of healthy eating;

- construct factual knowledge on healthy eating;

- develop capacity to make healthy eating choices;

- develop an understanding of scientific inquiry.

The scenario lasts 3 weeks and is composed of nine lessons. To conduct the exercise, we have chosen the second lesson, whose specific objectives are for students to identify the inquiry methods to be used and plan the investigation.

In particular, this lesson consists of six main activities:

- the class watches a short video providing an example of how an adult carried out an inquiry into her own eating habits;

- a plenary discussion is used to define methods to answer the inquiry questions identified in the previous lesson;

- a group activity is carried out to formulate the questions to be asked to the expert on nutrition;

- a group activity is performed to identify the types of data that best suit the investigation objectives;

- a debate about the healthiness of different food is carried out followed by instructions for a home activity;

- a conclusive plenary session aims to meta-reflect on the lesson achievements and its positioning within the whole scenario.

In the following, we describe how each approach could serve the purpose of sustaining the design of such a lesson.

\section{The 4SPPIces model}

Computer Supported Collaborative Blended Learning (CSCBL) scripts are a particular type of Collaborative Blended Learning (CBL) design that combine formal and informal activities occurring across different spatial locations (in and beyond the classroom) supported by a variety of technologies (cameras, computers, etc.) (Pérez-Sanagustín et al. 2012b). The major difficulty when addressing the design of CSCBL scripts refers to the selection of a technological support aligned with the targeted learning objectives. 4SPPIces is a conceptual model conceived to provide practitioners (experts in education) and technicians (knowledgeable about available technologies) with an implementation methodology to support and facilitate the design of CSCBL scripts, ensuring a balance between technology and education.

4SPPIces identifies four factors: the Space (S), the Pedagogical Method (PM), the Participants $(\mathrm{P})$ and the History $(\mathrm{H})$. Each factor is composed of a set of facets. A set of questions epitomises the aspects included in the facets, aiding the recognition of relevant issues that could affect the final learning design. High school teachers have applied 4SPPIces to design the implementation of a real educational practice for the subject of Geography. The design was evaluated in a case study involving 34 students and two teachers. The results showed the impact of considering 4SPPIces on enhancing 
and extending their previous practices and, consequently, reaching additional learning and motivational benefits (Pérez-Sanagustín, Emin and Hernández-Leo 2012).

In the case of the "Healthy Eating" scenario, the design process using 4SPPIces would be as follows (Figure 1). The Pedagogical Method (PM) describes a sequence of learning and teaching activities. The lesson of the "Healthy Eating" scenario has been structured into six different activities of the PM with different timings (see PM in Figure 1). For each activity, it is specified whether it is individual (P2) or not (P1, P3, P4, P5 and P6). Although it is not shown in the figure, the material provided for (incomes) or produced by (outcomes) the students represents the data flow that integrates the activities in a sequence. For example, in P3 ("propose a question in groups"), the income data are the inquiry methods agreed by the entire group in the previous activity, while the questions generated by each group are the outcomes.

The Participants $(P)$ factor specifies who participates in the learning activity and where they are located, in this case one teacher, one nutritional expert and 28 pupils. Each participant is associated with a task and to a particular location. The pupils and the teacher are located in the classroom, while the nutritional expert communicates with the students via e-mail.

The Space $(S)$ defines the planned environment where the learning activity is going to take place. In the example there are two physical spaces, classroom and home, and one virtual space corresponding to the toolkit used by the students to store their evidence. Next to this, the technological support employed for the investigation is specified: netbook with Internet connection used in class, camera for

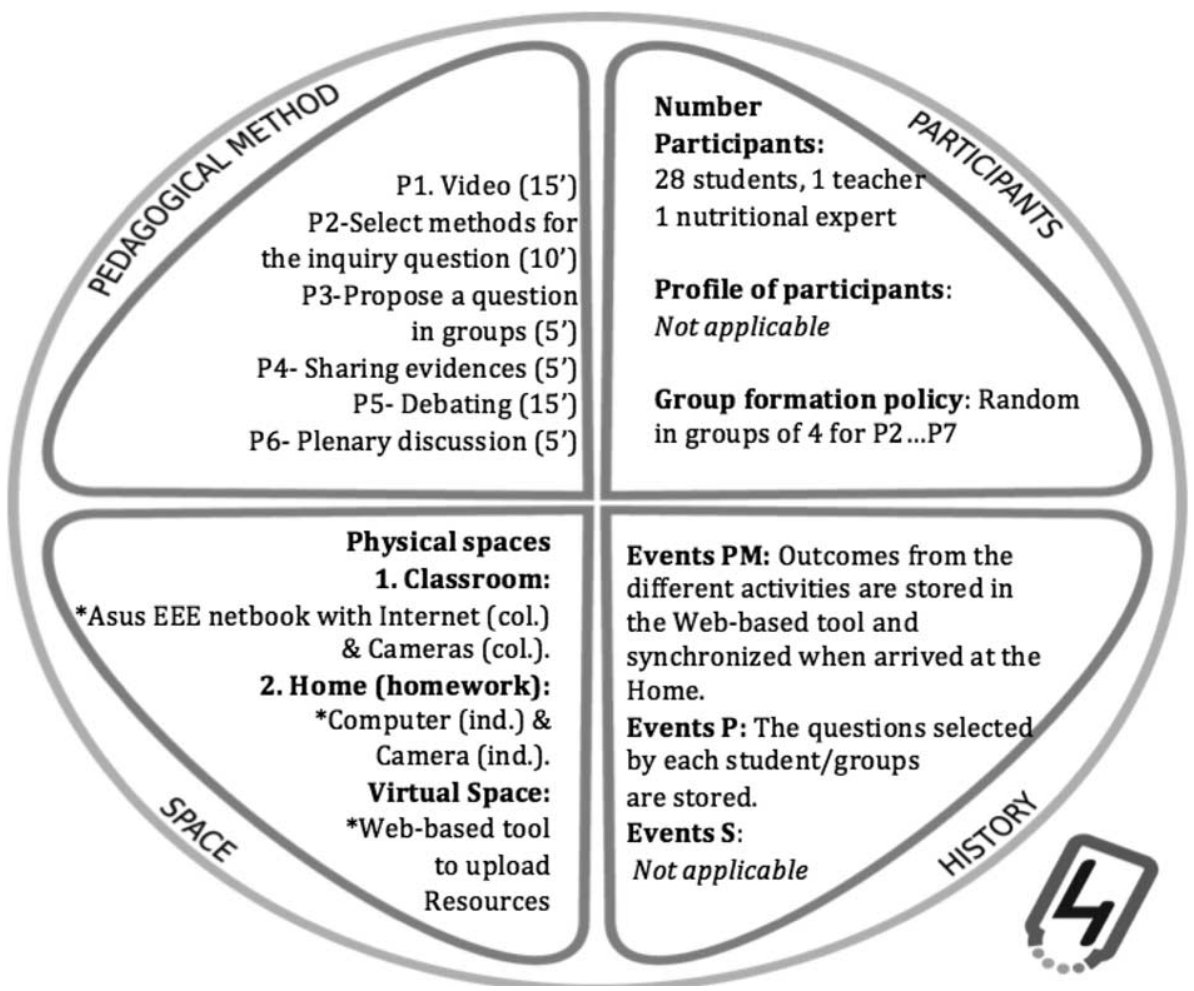

Figure 1. Using the 4SPPIces model within LdShake to support design conversations between practitioners and technicians. 


\section{Persico et al.}

gathering evidence at home and a computer to upload the evidence and select the inquiry methods. For each technological support, it is specified whether it will be used in groups (the projector in P1) or individually (netbooks in P2).

Finally, the History $(H)$ models what is likely to be varied during the activity enactment that requires flexible management. This factor models the relationships between the learning flow of the PM, the $\mathrm{P}$ and the $\mathrm{S}$ that might affect the activity enactment. The $\mathrm{H}$ expresses the need for a technological setting to store and share the resources generated by each participant that can be accessed from any of the spatial locations involved in the activity. Typically, a technician should identify the technological setting that best supports all the factors and their relationships.

To support collaboration between practitioners and technicians in implementing CSCBL scripts, the model has been integrated into a tool, called LdShake, which enables social sharing, co-editing, commenting and tagging educational designs (Hernández-Leo et al. 2011). The combination of LdShake and 4SPPIces (4SPPIces model offered as a template) provides a virtual space in which practitioners, technicians and other stakeholders, such as researchers, can have conversations about CSCBL designs when considering elements defined in the model.

\section{The 4Ts approach}

The 4Ts model has been developed to support pedagogical planning and decisionmaking in the Computer Supported Collaborative Learning (CSCL) design process. An extensive description of the development process and rationale, which led to identifying the 4Ts and a discussion of the 4Ts components, can be found in Pozzi and Persico (2013). The model looks at Task, Teams, Technology and Time as the four main components that the CSCL designer needs to focus on in his/her decisionmaking process. While designing an online collaborative learning activity, s/he defines the nature of the Task students will be asked to carry out, chooses the Teams' composition and interaction modes, and identifies the phases of the activity by providing the overall Time schedule. Technology, that is, the medium through which interactions will occur, is also a crucial component the designer is required to select and configure before the CSCL process starts. In the 4Ts model (Figure 2), the designer juggles with these four components, in no pre-determined or mandatory order: each decision concerning any of the four dimensions is influenced by the others and, reciprocally, impacts on them, so that each time the designer takes a decision, s/he has to go back to the other dimensions, to check what the consequences are. Even if a systematic evaluation of the 4Ts approach has not yet been carried out, this approach has been extensively used by its authors and their collaborators in different contexts and at different levels: in particular, the 4Ts have been used both to elicit designs while planning online activities, modules and courses, and to communicate the final designs to the tutors in charge of delivering the same activities/modules/courses. In addition, tutors have often used the 4Ts as a sort of guiding template to structure instructions for students on how to carry out the proposed activities.

In designing the lesson of the "Healthy Eating" scenario, the use of the 4Ts approach would require the designer to focus mainly on the following aspects:

- the various activities that participants need to carry out during the lesson, these would be the Tasks; 


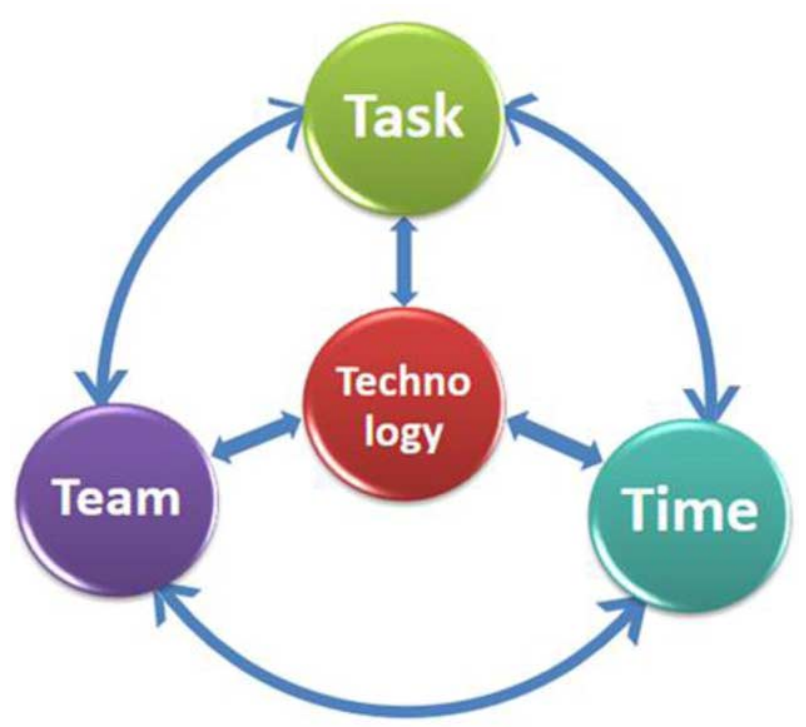

Figure 2. The 4Ts approach to support CSCL design processes.

- for each Task, the designer needs to define the most adequate social structure. In this lesson, for example, some of the Tasks should be carried out by small groups, others would involve the whole class, yet others are meant to be carried out individually by each student. For all the social structures, the designer needs to define size and number of teams, but also the presence of teachers and external experts and their role (if any) in the task;

- as far as Technology is concerned, the designer needs to define the various system functionalities the students will use, to consider their different affordances and to make his/her decisions based on a SWOT (Strengths, Weaknesses, Opportunities and Threats) ${ }^{6}$ analysis;

- the Time component is the expected length of time needed to carry out the various phases of each Task.

Although the selected lesson does not take full advantage of the 4Ts affordances, because many of its activities are not collaborative ones, the 4Ts model allows the designer to describe the lesson and its activities (Pozzi and Persico 2013).

\section{The e-Design Template}

The e-Design Template is a pedagogical model developed on constructivist principles from a range of other guides and models. It is intended to support practitioners when creating learning designs for e-learning and when reviewing and sharing learning designs. The template embeds principles to guide the development of quality elearning and entails four phases of scaffolding to support the development of learners into self-organised learners. The template has been used with novice e-learning designers and has been found useful to support the development of structured online activities that include both tutor managed and student managed activities. Research and evaluation of the use of this template by practitioners is still ongoing. 
Its best practice principles (with some of the key writers) are as follows (Walmsley 2011):

- e-Learning is designed in timed chunks that emphasise time on task and expectations (Gagné, Briggs, and Wager 1992);

- e-Learning is assessed using a range of approach types (self /peer/tutor assessment) and format options (multiple choice, essay, report, project, etc.) (Nicol 2009; Waterfield and West 2006);

- e-Learning includes a variety of interaction types between student/ tutors/ peers/ externals (Laurillard 1993);

- e-Learning is accessible, activity-led, collaborative and designed in phases that support, scaffold and increase learner independence (Coomey and Stephenson 2001; Race 2010; Swan 2005).

The principles are illustrated in Figure 3.

The e-Design Template can be used to guide planning and development of learning designs for both face-to-face and online environments and for short, single sessions as well as longer periods of learning. In addition, the Template can be used to plan learning using a specific tool or technology.

The "Healthy Eating" scenario, and in particular the lesson chosen for our exercise, is largely based on face-to-face activities with some use of technology for presentation, data collection and some group tasks. To do the exercise, we have expressed and mapped the activities of the lesson on the e-Design Template and on the principles outlined above.

The results of this exercise are represented in Table 1.

This mapping exercise shows that the "Healthy Eating" lesson uses some, but not all, of the e-learning principles above, and this may offer opportunities for reflection

Best Practice Principles for e-Learning

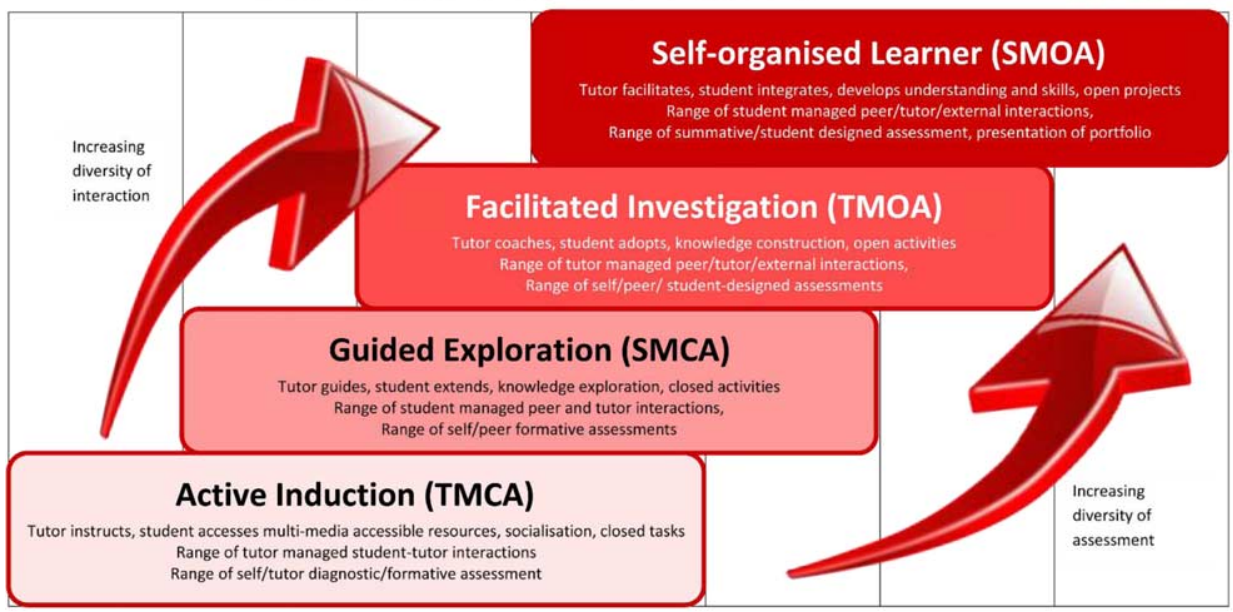

\begin{tabular}{l|l|l|l|l|l|l|l|l|l|l|} 
Week 1 & Week 2 & Week 3 & Week 4 & Week 5 & Week 6 & Week & Week 8 & Week 9
\end{tabular}

Figure 3. The e-Design Template to support e-learning design processes. 
Table 1. Mapping the lesson on the e-Design Template.

\begin{tabular}{|c|c|c|c|}
\hline $\begin{array}{l}\text { Active induction/stimulus } \\
\text { (tutor managed, closed activities) }\end{array}$ & $\begin{array}{l}\text { Guided exploration } \\
\text { (student managed, closed activities) }\end{array}$ & $\begin{array}{c}\text { Facilitated investigation } \\
\text { (tutor managed, open } \\
\text { activities) }\end{array}$ & $\begin{array}{l}\text { Self-organised learner } \\
\text { (student managed, } \\
\text { open activities) }\end{array}$ \\
\hline \multicolumn{4}{|l|}{ 1. Watch video $(1-3=15$ mins $)$} \\
\hline \multicolumn{4}{|l|}{$\begin{array}{l}\text { TS (tutor-student) interaction } \\
\text { NO assessment }\end{array}$} \\
\hline \multicolumn{4}{|l|}{ 2. SS ask questions about video $(1-3=15$ mins $)$} \\
\hline \multicolumn{4}{|l|}{$\begin{array}{l}\text { TS and SS (student-student) interaction } \\
\text { NO assessment }\end{array}$} \\
\hline \multicolumn{4}{|l|}{ 3. Teacher summarises $(1-3=15$ mins $)$} \\
\hline \multirow{2}{*}{\multicolumn{4}{|c|}{$\begin{array}{l}\text { TS interaction } \\
\text { NO assessment }\end{array}$}} \\
\hline & & & \\
\hline & SS interaction & & \\
\hline & NO assessment & & \\
\hline & 5. Groups discuss and agree questions to ask experts ( 5 mins) & & \\
\hline & SS and SE interaction & & \\
\hline & NO assessment & & \\
\hline & 6. Group discusses how to collect good data $(6+7=5 \mathrm{mins})$ & & \\
\hline & SS interaction & & \\
\hline & NO assessment & & \\
\hline & 7. Teacher shows sample data and groups discuss and agree good & & \\
\hline & $\begin{array}{l}\text { data }(6+7=5 \text { mins }) \\
\text { SS and TS interaction }\end{array}$ & & \\
\hline & $\begin{array}{l}\text { SS and TS interaction } \\
\text { NO assessment }\end{array}$ & & \\
\hline \multicolumn{4}{|l|}{ 8. Teacher compares responses about good data ( 5 mins) } \\
\hline \multirow{2}{*}{\multicolumn{4}{|c|}{$\begin{array}{l}\text { TS interaction } \\
\text { Formative feedback }\end{array}$}} \\
\hline & & & \\
\hline \multirow{2}{*}{\multicolumn{4}{|c|}{$\begin{array}{l}\text { 9. Teacher leads discussion and provides guidelines for } \\
\text { data collection ( } 15 \text { mins })\end{array}$}} \\
\hline & & & \\
\hline \multicolumn{4}{|l|}{$\begin{array}{l}\text { TS and SS interaction } \\
\text { NO assessment }\end{array}$} \\
\hline \multicolumn{4}{|l|}{ 11. Teacher summary ( 5 mins) } \\
\hline \multirow{2}{*}{\multicolumn{4}{|c|}{ TS interaction }} \\
\hline & & & \\
\hline
\end{tabular}




\section{Persico et al.}

to the tutor. The activities are clearly timed and follow a clear structure; there is one opportunity for student feedback; the majority of the interactions are between the tutor and the students; the activities are engaging, include collaboration and focus on the first two scaffolding phases (Active Induction and Guided Exploration) giving the students opportunities to manage some of their own learning. The e-learning principles and template offer a simple and quick reminder of some key features of quality learning that encourages the designer to create active, collaborative learning activities that develop students' independent learning skills.

\section{The Design Principles Database}

The DPD has been developed to capture, coalesce and synthesise design knowledge (http://edu-design-principles.org). This approach is based on an extensive collection of principles for socio-constructivist learning design, whose reciprocal relations are organised in a map: four meta-principles (Help Students Learn from Each Other, Make Contents Accessible, Make Thinking Visible, Promote Autonomous Life Long Learning), a set of pragmatic principles and a number of specific principles. Between 2001 and 2008, the DPD was open to contributions from the public: designers of educational technologies (teachers, curriculum designers, researchers, etc.) were able to publish, connect, discuss and review design ideas. In this manner, it served both as a collaborative knowledge building tool for the community (Kali 2006), and as means for promoting design-based research (Kali 2008). In our exercise, the DPD was used to analyse the lesson of the "Healthy Eating" scenario. To do so, specific features of the activities of this lesson were inspected in terms of the rationales used to design them, as can be determined by the description of the activities (Anastopoulou et al. 2012), and by design notes that were made available to us for the purpose of this analysis. After the rationales were elicited, a design principle with a similar rationale in the DPD was sought. Table 2 represents the results of this exercise: four features in the "Healthy Eating" lesson and the corresponding design principles from the DPD that were found relevant to them.

The value of such an analysis is that instead of focusing on What is done in each step of a learning design, and How technology is used, it makes it possible to easily communicate Why each step was designed in that way, and how it connects to theory and to well-established design knowledge. This type of analysis, when conducted a posteriori - after the scenario has already been designed and developed (as in this exercise) - can serve as a reflection and synthesis tool. It can help designers reflect back on their rationales for designing their activities, and assist them to define and acknowledge the theoretical background of their work. By reviewing features from other learning scenarios that are connected in the DPD to the same design principles, designers can also see how others have tackled similar design challenges.

Normally, however, the DPD is meant to be used a priori, while designing TEL activities. In this manner, it can help guide novices in a design process as part of a structured design course or workshop.

\section{The Design Narrative approach}

A Design Narrative (Mor 2011, 2013) is an account of critical events in a design experiment from a personal, phenomenological perspective. It is focused on design in the sense of problem solving, describing a problem in the chosen domain, the actions 
Table 2. Features in the "Healthy Eating" lesson and corresponding design principles from the DPD.

\begin{tabular}{|c|c|}
\hline Feature in the Healthy Eating lesson & Relevant pragmatic design principle from the DPD \\
\hline $\begin{array}{l}\text { Modelling video: } \\
\text { "a short video to the class of an adult describing (modelling) their own } \\
\text { personal inquiry on their eating well wheel" }\end{array}$ & $\begin{array}{l}\text { Model scientific thinking } \\
\text { This principle calls to include in learning environments examples of how } \\
\text { scientists work, and thus model to students how they can discover new views } \\
\text { to add to their mix of ideas and how they can detect failures, deal with } \\
\text { feedback, and communicate with others (Linn, Bell, and Davis 2004) }\end{array}$ \\
\hline $\begin{array}{l}\text { List of inquiry methods in the Toolkit }{ }^{8} \text { : } \\
\text { "The teacher asks everyone in the class to look at the list of inquiry } \\
\text { methods in their Toolkits and suggests which would be the most } \\
\text { appropriate to answer this question." }\end{array}$ & $\begin{array}{l}\text { Communicate the rich diversity of inquiry } \\
\text { This principle calls on designers to expose learners to the rich diversity of the } \\
\text { inquiry process. Far too often students leave science class with an image of } \\
\text { inquiry as dogmatic and inflexible or abstract and incomprehensible (Linn, } \\
\text { Bell, and Davis 2004). Technology-enhanced learning environments can help } \\
\text { students become aware of the diversity of science inquiry by engaging students } \\
\text { in a variety of inquiry processes. }\end{array}$ \\
\hline $\begin{array}{l}\text { Collating student responses as resources for discussion: } \\
\text { "Each group copies and annotates the photos on their computers ... When } \\
\text { they have all finished, the teacher displays and compares their selections on } \\
\text { the whiteboard. They discuss why some photos are better than others" }\end{array}$ & $\begin{array}{l}\text { Reuse student artefacts as resources for learning } \\
\text { This principle advocates the use of artefacts developed by learners, as } \\
\text { resources for further learning of their peers. In this manner, the artefacts, } \\
\text { created by individuals, or in groups, can support the learning of those who } \\
\text { struggled to interpret and process a certain body of knowledge, as well as } \\
\text { others, who can benefit from the products of this process (Kali, Levin-Peled, } \\
\text { and Dori 2009). }\end{array}$ \\
\hline
\end{tabular}




\section{Persico et al.}

taken to resolve it and their unfolding effects. It provides an account of the history and evolution of a design over time, including the research context, the tools and activities designed, and the results of users' interactions with these. It portrays the complete path leading to an educational innovation, not just its final form including failed attempts and the modifications they espoused. Design narratives have been used extensively by several projects as an intuitive form of sharing design knowledge between practitioners (Mor et al. 2010; Mor, Warburton, and Winters 2012).

The Design Narrative for the lesson of the "Healthy Eating" scenario was developed a posteriori through a dialogue between Yishay Mor and Stamatina Anastopoulou, the researcher who originally led the experiment. ${ }^{7}$

The Design Narrative adds some important contextual information, which does not appear in the original design documents. For example, it notes the warm and open relationships between the teacher and the students, and between the teacher and other school staff. It also mentions the fact that this was the highest performing class in the year group, and provides information about the physical conditions in the science lab.

The narrative describes the activities for the Lesson as they were planned, but then identifies several obstacles that emerged when these were enacted, and recounts how the teacher and the researcher tried to deal with those. Some of these obstacles relate to physical conditions, such as sunlight that interfered with viewing images on the whiteboard. Some of them relate to socio-pedagogical conventions: students did not expect the pictures they took to be presented to the whole class, and were embarrassed about exposing their personal habits. Some obstacles related to the teacher's understanding of the inquiry method, and her ability to articulate the design and its rationale to the students.

Due to the obstacles that were encountered, the narrative does not provide conclusive evidence for or against the learning design and its effectiveness. However, it does highlight several meta-issues, which need to be considered when designing similar activities:

- Personal inquiry can become too personal. It is important to account for the affective dimension of learners' personal investment in the topic of inquiry. The design needs to be sensitive to issues of privacy, confidence and trust.

- Introducing a new pedagogy implies a new set of socio-pedagogical conventions: what is legitimate in classroom interaction, what is expected, and what is assumed. These need to be negotiated explicitly.

- Not only the teacher, but also the students need to take part in the design process, and be fully committed to the pedagogical approach and the activity design. This was the main implication of the study and informed the next cycle of design.

\section{Discussion: what can we learn from multiple approaches to learning design?}

This paper presents five different approaches developed to sustain learning design with the aim of improving quality and effectiveness of the learning process. Although these approaches are very different from each other, as we discuss below, they all serve a mutual goal of supporting the learning design process by providing guidelines for the design decisions and/or by guiding reflection on design choices. In other 
words, each of the five approaches provides a conceptual framework to assist educators in making design decisions and reflect on the rationale for such decisions. These decisions regard different problematic questions of the design process: from very broad issues, such as how to design activities that connect to personally relevant contexts, to specific matters, such as how to design student managed guided exploration. Two of the approaches (4SPPices and DPD) do this with the support of technology, since each of them has been embedded in a tool, while in the other three cases (4Ts, e-Design Template and Design Narrative) they are not implemented in a tool (at least, at the moment). In any case, none of these approaches aims to automate the implementation of a delivery environment for conducting the learning activities with students. This differentiates them from other design approaches, such as the ones described in Prieto et al. (2013), that focus on lower level design phases and are embedded in tools that provide support towards the delivery of teaching and learning activities.

The choice of applying the approaches described in this paper to the same lesson example is meant to facilitate the reader in appreciating the differences and similarities between them. Of course the exercise is not "authentic," since the lesson had already been planned and thus each approach was not really used to support the design process, but rather to demonstrate how it works and to reflect, a posteriori, on its main strengths and weaknesses. Besides, the Rashomon idea has some limitations. One of these is the fact that the range of approaches considered is obviously limited to those proposed by the researchers who accepted to participate in this experiment, that is, the authors of this paper, and this implies that the paper cannot be exhaustive or representative of the whole research area. Another limitation is due to the fact that not all the approaches lend themselves equally well when applied to the chosen lesson.

Nonetheless, looking at the same lesson from five different perspectives allows us to appreciate the distinctive features of the approaches, as well as some similarities between them.

To begin with, the 4SPPices model and the 4Ts have several similarities: first of all, the fact that they have been devised for collaborative learning contexts; second, they are both based on the idea of identifying aspects the designer should focus on to make his/her decisions. For the 4SPPices, these aspects are Space, Pedagogical Method, Participants, and History. The 4Ts, instead, are based on Task, Time, Teams and Technology. It should be noted that the Pedagogical Method of the former includes the Task of the latter, Space encompasses Technology, and Participants include Teams. A closer look at the two approaches reveals that the former concerns design at macro-level, while the four Ts have been used both in macro-design (entire courses) and in micro-design (thus reaching a fine grained definition of individual activities). In addition, while the 4SPPices model makes the role of Space explicit, 4Ts emphasises the importance of Time when planning learning designs.

On the other hand, the e-Design Template and the DPD seem to share a common basic idea. The idea is that there are Principles for good design and any approach to support learning design should make them explicit, while encouraging and helping the designers to bear these principles in mind and apply them (or at least consciously ignore them). These two approaches thus provide designers with a structure for the application of these principles, pointing out relevant principles to designers while they ideate an activity. However, as described in the respective sections, the principles chosen by the two approaches are different: for example, some of the DPD principles 


\section{Persico et al.}

for collaborative learning are: "engage learners in authentic problem solving"; "promote productive interactions", "encourage learners to learn from each other", etc., while the e-Design Template proposes the four general design principles of Figure 3 to inform learning design that promotes a gradual development of learners' self-regulation. These should aim to make students more and more autonomous in organising and assessing their own learning.

The idea of suggesting appropriate design principles to designers may appear a rather obvious standpoint, but it is not: in spite of the fact that decades of work in this research area have yielded a wealth of results, or perhaps just because of this wealth, it often happens that in many formal learning contexts such principles are simply ignored. Although the four key principles of the e-Design Template are very different in nature from those adopted in the DPD, both regard the objective of developing students' self-regulated learning abilities as an overarching one, because of its importance in empowering students in view of lifelong learning needs. The application of these two approaches in our Rashomon exercise leads to an analysis of the lesson and its component activities in view of the design principles underlying each approach. In the first case, the analysis reveals that only the first two phases of the e-Design Template were applied in this lesson, which is coherent with the fact that this is only the second of a series of nine lessons making up the whole pedagogical plan. As for the DPD, the analysis shows which pragmatic design principles are applied in the four phases of the activity, thus providing a (possible) rationale for the design choices made by the designer.

Among the five approaches considered in this paper, only the last, the Design Narrative approach, is intended to be used ex-post as in our exercise, the others, instead, are meant to support reflection during the decision-making process. This feature of the Design Narrative approach allows not only to promote reflections on the appropriateness of the designer's choices, but also to gather information about the perceived effectiveness of the design, as well as the problems encountered during enactment. This approach is also more general than most of the others, because it is not tied to any particular learning theory.

Table 3 provides a synopsis of the main characteristics of the five approaches.

Looking at Table 3, one may observe that the five approaches share a common aspect, that is, the fact that they focus on the first three phases of the ADDIE model (Analysis, Design, Development, Implementation, Evaluation), with no ambition to move on as far as supporting enactment, even if some of the approaches described here have been embedded in tools (LdShake for the 4SPPIces, and the DPD), whose aim is to support co-design or production of sharable artefacts. Recent research work has put more emphasis on other phases of the complete lifecycle of an educational intervention. According to the forward-oriented approach to design for learning (Dimitriadis and Goodyear 2013), approaches should not only consider activity configuration, but also orchestration, reflection and eventual redesign, that is, phases that take into account the enactment of the activity that has been configured. A survey of the current debate regarding design for orchestration can be found in (Dillenbourg et al., 2012).

\section{Conclusions}

To conclude this discussion, the leading relevant question is: "what are sensible criteria to choose one of these approaches rather than the others?" As so often 
Table 3. Comparing the five approaches.

\begin{tabular}{|c|c|c|c|c|c|}
\hline Picture & Name & $\begin{array}{l}\text { Relevant } \\
\text { learning theory }\end{array}$ & Focus on $\ldots$ & Overview & Tool \\
\hline & 4SPPices & Socio-constructivism & $\begin{array}{l}\text { Four factors: Space, } \\
\text { Pedagogical Method, } \\
\text { Participants, and History }\end{array}$ & $\begin{array}{l}\text { The 4SPPIces model is used to support and } \\
\text { facilitate the design of CSCBL scripts entailing } \\
\text { design conversations between practitioners and } \\
\text { technicians. }\end{array}$ & $\begin{array}{l}\text { In principle not } \\
\text { dependent on a } \\
\text { particular tool; at } \\
\text { the moment it is } \\
\text { embedded in } \\
\text { LDshake }\end{array}$ \\
\hline & $4 \mathrm{Ts}$ & Socio-constructivism & $\begin{array}{l}\text { 4Ts: Task, Task, Teams, } \\
\text { Technology, Time }\end{array}$ & $\begin{array}{l}\text { The } 4 \text { Ts (Task, Teams, Technology and Time) } \\
\text { are used here as a planning framework to assist } \\
\text { practitioners and novice teachers in the design } \\
\text { of collaborative learning activities. }\end{array}$ & None \\
\hline & $\begin{array}{l}\text { e-Design } \\
\text { Template }\end{array}$ & Constructivism & $\begin{array}{l}\text { Best Practice Design } \\
\text { Principles }\end{array}$ & $\begin{array}{l}\text { The e-Design Template is used as a } \\
\text { pedagogic framework to embed e-learning } \\
\text { principles aimed at developing learners' } \\
\text { self-regulation in the lesson design. }\end{array}$ & None \\
\hline & DPD & Socio-constructivism & $\begin{array}{l}\text { A network of Design } \\
\text { Principles: four } \\
\text { meta-principles; several } \\
\text { pragmatic principles and } \\
\text { specific principles }\end{array}$ & $\begin{array}{l}\text { The Design Principles are used to map key } \\
\text { learning design principles to the lesson. }\end{array}$ & $\begin{array}{l}\text { Design Principles } \\
\text { Database }\end{array}$ \\
\hline II & $\begin{array}{l}\text { Design } \\
\text { Narrative }\end{array}$ & All & $\begin{array}{l}\text { Critical aspects in the } \\
\text { design decisions; design } \\
\text { seen as a problem } \\
\text { solving activity. }\end{array}$ & $\begin{array}{l}\text { The Design Narrative is a reflection on the whole } \\
\text { context and process of developing and delivering } \\
\text { the lesson. }\end{array}$ & None \\
\hline
\end{tabular}




\section{Persico et al.}

happens, not only is there no "one size fits all" answer, but in this case we can even say that there is no need to choose just one of the approaches, given that some of them can be used in combination with others, since they cover different aspects of the design process. The Design Narrative approach, for example, can be used together with any of the others. Similarly, there is no specific reason why one designer should not use the DPD to inspire his/her high level pedagogical decisions and then focus on the 4Ts to plan the structure of the collaborative activities.

Given this premise, in the following we try to make some selection criteria more explicit.

The first two criteria are very subjective ones: the extent to which one designer feels "in tune" with the approach itself, and the extent to which the approach and, when available, the tool associated with it, turns out helpful and effective when used in practice. This means that while this paper aims to provide an overview of the five methods, trying one approach out is the best way to assess it and understand it more thoroughly, because use allows an estimation of the balance between the costs (in terms of effort needed to use the method) and the benefits of using it. It goes without saying that the effort needed to initially come to grips with the method is an investment that should be counterbalanced by the advantages in the long term.

In addition to these two important, but very subjective criteria, there are also some more objective ones. For example, as already mentioned, the 4SPPSices, 4Ts and DPD have been developed with socio-constructivist learning processes in mind, while the e-Design Template seems to be prominently inspired by constructivist learning theories, both for individual and collaborative learning. This entails that they should be chosen only when these kinds of approaches are deemed fitting with the learning needs and context.

The availability of a tool that supports the use of some of the above approaches is undoubtedly an asset in favour of those approaches, because such tools facilitate their users in using the approach and respecting its internal coherence. Hence, it stands to reason that tools, which support the designers' choices throughout the development phases up until enactment, providing a complete environment supporting the whole process, will further facilitate designers, especially those with few technological skills. It is no coincidence, therefore, that the Rashomon II paper, companion of this paper (Prieto et al., 2013), focuses on a range of existing tools that allow designers to represent, share, and in some cases, enact their plans with students. The logical continuity of the two phases investigated by the two Rashomon papers of this issue is evident, but their actual integration into one coherent theoretical framework and its practical feasibility into one digital system is still the object of research in learning design.

\section{Acknowledgements}

This work has been partially supported by the Learning Design Theme Team funded by the European Union through the STELLAR Network of Excellence for Technology Enhanced Learning (FP7-IST-231913) and by the METIS project ("Meeting teachers co-design needs by means of integrated learning environments"), funded under the Lifelong Learning Programme (Transversal programme: KA3 - ICT Multilateral projects). 


\section{Notes}

1. The "Learning Design Grid (LDG)" Theme Team (http://www.ld-grid.org/) was funded by the STELLAR Network of Excellence (7FP) from 2011 to 2012 and this RLT issue is one of its results.

2. http://metis-project.org/

3. http://www.jisc.ac.uk/

4. Many authors in the field of TEL use the terms "scenario" and "learning scenario" in a generic sense to denote any situation, real or imagined, where a learning intervention can either be envisaged or might be required in order to meet given educational needs. According to Peter and Vantroys (2005), for example, the pedagogical scenario "defines the activities which must be done by the learners and the tutors, the sequencing of these activities as well as the learning objects and tools that should be provided to the different actors". Schneider (2003) defines a pedagogical scenario as "a sequence of phases within which students have tasks to do and specific roles to play." A different perspective is assumed by Pernin and Lejeune (2006), who define their learning scenario as: "a description, carried out a priori or a posteriori, of the playing out of a learning situation or a unit of learning aimed at the acquisition of a precise body of knowledge through the specification of roles and activities, as well as knowledge handling resources, tools, services and results associated with the implementation of the activities ...". In the context of this paper it is enough to say that the "Healthy Eating" scenario consists of the description of nine lessons, which guide students through an inquiry into their eating habits.

5. The PI project ("Personal Inquiry: Designing for Evidence-based Inquiry Learning across Formal and Informal Settings") was a 3 year project (2007-2010) led by the University of Nottingham and The Open University, UK, and funded by the ESRC and EPSRC UK research councils under their TLRP-TEL initiative. The aim of the project was to support children aged 11-14 in coming to understand themselves and their world through scripted personal inquiry learning. The "Healthy Eating" activity was one of the scenarios examined by the project.

6. SWOT (Strengths, Weaknesses, Opportunities and Threats), see http://en.wikipedia.org/ wiki/SWOT_analysis

7. The full text of the narrative is available at: http://www.ld-grid.org/resources/learningdesigns/pi-project-healthy-eating-activity/healthy-eating-design-narrative

8. The Toolkit is a technological tool used in the PI project to support the practice of inquiry.

\section{References}

Anastopoulou, S. et al., (2012) 'Creating personal meaning through technology-supported science inquiry learning across formal and informal settings', International Journal of Science Education, vol. 34, no. 2, pp. 251-273.

Botturi, L. et al., (2007) 'Comparing visual instructional design languages: a case study', in Handbook of Visual Languages in Instructional Design: Theories and Practices, eds L. Botturi \& T. Stubbs, Idea Group, Hershey, PA, pp. 315-343.

Britain, S. (2004) A review of learning design: concept, specifications and tools. A report for the JISC E-learning Pedagogy Programme, [online] Available at: http://www.jisc.ac.uk/uploaded_documents/ACF1ABB.doc

Conole, G. (2013) Designing for learning in an open world, Springer, New York.

Coomey, M. \& Stephenson, J. (2001) 'Online learning: it's all about dialogue, involvement, support and control according to the research', in Teaching and Learning Online: New Pedagogies for New Technologies (Creating success), ed. J. Stephenson, Kogan Page, London, pp. 37-52.

Dillenbourg, P. et al., (2012) 'Design for classroom orchestration', Computers \& Education, [online] Available at: http://www.sciencedirect.com/science/article/pii/S0360131512002540, DOI: $10.1016 /$ j.compedu.2012.10.026.

Dimitriadis, Y. \& Goodyear P. (2013). 'Forward-oriented design for learning: Illustrating the approach', Research in Learning Technology, vol. 21. DOI: 10.3402/rlt.v21i3.19909.

Dobozy, E. (2011) 'Typologies of learning design and the introduction of a "LD-Type 2" case example', eLearning Papers, vol. 27, no. 27, pp. 1-11. 


\section{Persico et al.}

Duschl, R. A. Schweingruber, H. A. \& Shouse, A. W., (eds) (2007) Taking science to school: learning and teaching science in grades $K-8$, National Academies Press, Washington, DC.

Earp, J. \& Pozzi, F. (2006) 'Fostering reflection in ICT-based pedagogical planning', Proceedings of The First International LAMS Conference 2006-Designing the Future of Learning, Sydney, Australia, pp. 35-44, [online] Available at: http://lams2008. lamsfoundation.org/pdfs/Earp_Pozzi_LAMS06.pdf

Gagné, R. M., Briggs, L. J. \& Wager, W. W. (1992) Principles of instructional design, 4th edn, Harcourt Brace Jovanovich, Fort Worth, TX.

Goodyear, P. \& Retalis, S. (2010) Technology-enhanced learning: design patterns and pattern languages, Sense Publishers, Rotterdam.

Gutiérrez, S. et al., (2007) 'A swarm approach for automatic auditing of pedagogical planning', Proceedings of the Seventh IEEE International Conference on Advanced Learning Technologies (ICALT) 2007, pp.136-138, [online] Available at: http://ieeexplore.ieee.org/ search/searchresult.jsp?searchWithin=p_Authors..QT.Valigiani,\%20G..QT.\&newsearch= partialPref

Hernández-Leo, D., et al., (2011) 'LdShake: learning design solutions sharing and co-edition', Computers \& Education, vol. 57, no. 4, pp. 2249-2260.

Kali, Y. (2006) 'Collaborative knowledge building using the design principles database', International Journal of Computer Support for Collaborative Learning, vol. 1, no. 2, pp. 187-201.

Kali, Y. (2008) 'The design principles database as means for promoting design-based research', in Handbook of design research methods in education, eds A. E. Kelly, R. A. Lesh \& J. Y. Baek, Routledge, New York, pp. 423-438.

Kali, Y., Levin-Peled, R. \& Dori, Y. J. (2009) 'The role of design-principles in designing courses that promote collaborative learning in higher-education', Computers in Human Behavior, vol. 3, no. 1 , pp. 55-65.

Laurillard, D. (1993) Rethinking university teaching: a framework for the effective use of educational technology, Routledge, London.

Laurillard, D. (2012) Teaching as a design science: building pedagogical patterns for learning and technology, Routledge, Abingdon.

Linn, M. C., Bell, P. \& Davis, E. A. (2004) 'Specific design principles: elaborating the scaffolded knowledge integration framework', in Internet Environments for Science Education, eds M. C. Linn, E. A. Davis \& P. Bell, Lawrence Erlbaum Associates, Mahwah, NJ, pp. 315-340.

Lockyer, L., et al., (2009) Handbook of research on learning design and learning objects: issues, applications, and technologies (2 volumes), IGI Global, Hershey, PA.

Mor, Y., et al., (2010) 'Formative e-Assessment: case stories, design patterns and future scenarios', in Problems Investigations of E-Learning Patterns: Context Factors, Problems and Solutions, eds C. Kohls \& J. Wedekind, IGI Global, Hershey, PA, pp. 199-219.

Mor, Y. (2011) 'Design Narratives: An Intuitive Scientific Form for Capturing Design Knowledge in Education', 6th Chais Conference on Instructional Technologies Research: Learning in the Technological Era, Raanana, Israel, pp. 57-63.

Mor, Y. (2013) 'SNaP! Re-using, sharing and communicating designs and design knowledge using scenarios, narratives and patterns', in Handbook of Design in Educational Technology, eds R. Luckin et al., Routledge, London, UK.

Mor, Y. \& Craft, B. (2012) 'Learning design: reflections on a snapshot of the current landscape', Research in Learning Technology, vol. 20, Supplement: ALT-C 2012 Conference Proceedings, pp. 85-94.

Mor, Y., Warburton, S. \& Winters, N. (2012) 'Participatory pattern workshops: a methodology for open learning design inquiry', Research in Learning Technology, vol. 20, Supplement: ALT-C 2012 Conference Proceedings, pp. 163-175.

Nicol, D. (2009) 'Assessment for learner self-regulation: enhancing achievement in the first year using learning technologies', Assessment \& Evaluation in Higher Education, vol. 34, no. 3, pp. 335-352.

Pérez-Sanagustín, M., Emin, V. \& Hernández-Leo, D. (2012) 'Considering the space in the design of learning activities: the ISIS and 4SPPIces models applied to science inquiries', Proceedings of the 12th IEEE International Conference on Advanced Learning Technologies, Roma, Italy, pp. 159-163. 
Pérez-Sanagustín, M., et al., (2012a) 'Discovering the campus together: a mobile and computer-based learning experience', Journal of Network and Computer Applications, vol. 35, no. 1, pp. 176-188.

Pérez-Sanagustín, M., et al., (2012b) '4SPPIces: a case study of factors in a scripted collaborative-learning blended course across spatial locations', International Journal of Computer-Supported Collaborative Learning, vol. 7, no. 3, pp. 443-465.

Pernin, J-P. \& Lejeune, A. (2006) Models for the reuse of learning scenarios, "Imagining the future for ICT and Education", IFIP conference Proceedings, Ålesund, Norway, June 2006, [online] Available at: http://www-clips.imag.fr/arcade/User/jean-philippe.pernin/ recherche/download/PerninLejeune_IFIPAlesund2006_Paper.pdf

Peter, Y. \& Vantroys, T. (2005) 'Platform Support for Pedagogical Scenarios', Journal of Educational Technology and Society, vol. 8, no. 3, pp. 122-137.

Pozzi F. \& Persico D. (2013). 'Sustaining learning design and pedagogical planning in CSCL', Research in Learning Technology, vol. 21. DOI: 10.3402/rlt.v21i3.17585.

Prieto, L. P. et al., (2013) 'Learning design Rashomon II - exploring one lesson through multiple tools', Research in Learning Technologies, vol. 21. DOI: 10.3402/rlt.v21i3.20057.

Race, P. (2010) Making Learning Happen: A Guide for Post-Compulsory Education, 2nd edn, Sage Publications, London.

Reiser, R. A. (2001) 'A history of instructional design and technology: part II', Educational Technology Research and Development, vol. 49, no. 2, pp. 57-67.

Schneider, D. K. (2003) 'Conception and implementation of rich pedagogical scenarios through collaborative portal sites: clear focus and fuzzy edges'. Working paper prepared for an invited keynote address and workshops atICOOL, International Conference on Open and Online Learning, December 7-13, 2003, University of Mauritius, [online] Available at: http://tecfa.unige.ch/proj/seed/catalog/docs/icool03-schneider.pdf

Swan, K. (2005) 'A Constructivist model for thinking about learning online', in Elements of Quality Online Education: Engaging Communities, eds J. Bourne \& J. C. Moore, The Sloan Consortium, Needham, MA, [online] Available at: http://emergingonlinelearningtechnology. org/publications/books/pdf/interactions.pdf

The Larnaca Declaration on Learning Design (2012), [online] Available at: http://www. larnacadeclaration.org/

Vignollet, L., Martel, C. \& Burgos, D. (2008) 'Editorial: comparing educational modelling languages on the "Planet Game" case study', Journal of Interactive Media in Education, no. 2, [online] Available at: http://www-jime.open.ac.uk/jime/article/view/2008-16

Walmsley, H. (2011) Best Practice Models for e-Learning, [online] Available at: http:// bestpracticemodels.wiki.staffs.ac.uk/

Waterfield, J. \& West, B. (2006) Inclusive Assessment in Higher Education: A Resource for Change, [online] Available at: http://www.plymouth.ac.uk/pages/view.asp?page=10494 